\title{
Height and Economic Development in Italy, 1730-1980
}

\author{
By Franco PERACChi*
}

In this paper, I review evidence on the longrun relation between height and economic development in Italy. This has been done for several countries, but not for Italy. Yet, several reasons make this country an interesting case to consider.

After being at the center of the European economy during the Renaissance, Italy went through a long period of decline. By the time of political unification in 1861, Italy had become a peripheral economy. The country did not catch up with the rest of Europe for some time. Angus Maddison (1995) estimates Italy's GDP per capita to be 62 percent of that of the United Kingdom in 1820, falling to 45 percent in 1870.

Among European countries, Italy stands out for its wide and deep-rooted regional inequalities. Richard Eckaus (1961) estimates a 15 to 25 percent differential in income per capita between the North and the South in 1861, but the South itself was far from homogeneous. For the first few decades after unification there is no evidence of differential trends by region. Between 1891 and 1951, however, incomes in the South fell substantially relative to the other regions, especially those in the industrializing Northwest (Emanuele Felice 2006). In the early 1960s, Vera Lutz (1962) describes Italy as a dual economy where incomes in the South were less than half those in the North.

Precise assessment of long-run trends and regional inequalities is difficult, however. Few data are available for the pre-unification period. For the period between 1861 and WWI, a number of aggregate welfare indicators have been constructed (output and consumption per capita, life expectancy at birth, etc.), but their

\footnotetext{
* Faculty of Economics, University of Rome "Tor Vergata," via Columbia 2, 00133 Rome, Italy (e-mail: franco.peracchi@uniroma2.it). I thank Brian A'Hearn, Anne Case, Janet Currie, Angus Deaton, Luigi Guiso, and Chris Paxson for helpful discussions, and Paolo Malanima for providing his reconstruction of Italian GDP per capita. I also thank the Center for Health and Wellbeing at Princeton University for generous hospitality during fall 2006 and summer 2007, supported by National Institute of Aging grant P30 AG024361.
}

quality is still subject to debate. These indicators show improvements over time, especially after 1890 , but may mask different patterns at the regional level. More generally, detecting distributional effects of economic development is very hard because of the lack of disaggregate information.

It is precisely in this kind of cases that the use of height and other anthropometric data has been advocated, especially by economic historians (Robert Fogel 1994). Systematic differences in adult height are reliable indicators of differences in net nutrition (gross nutrition minus losses due to the disease environment) during the growing years, especially early childhood (Karry Silventoinen 2003). Because gross nutrition is tied to real incomes, systematic differences in adult height may also be informative about differences in real incomes. Though the height/income relation has often been emphasized, its nature and its stability over time and space deserve more scrutiny.

In this paper, I ask three questions: What are the long-run trends of mean height and real incomes in Italy? What do we know about height dispersion? What other aspects of the distribution of height changed with economic development? I focus on Italian males because no long-run information is available on female height.

\section{Data Sources}

For real incomes, I use the annual series of Italian GDP per capita at constant 1911 prices and current borders reconstructed by Paolo Malanima (2007). These data represent a bold attempt at unifying the scant evidence available before 1890 .

For height, I use three sources, each with its own peculiarities and problems. For the cohorts born between 1730 and 1840, I rely on the results of Brian A'Hearn (2003), based on a sample of about 8,000 soldiers from the infantry regiments of the Habsburg army recruited in Northern Italy during that period. The main statistical 
issues in these data are truncation from below due to a time-varying minimum height requirement and variation in the age at measurement. A'Hearn (2003) addresses these issues using a truncated maximum likelihood estimator based on the conventional assumption of normally distributed height.

For the cohorts born between 1846 and 1980, I use two datasets derived from the anthropometric measures taken during the compulsory examination to ascertain fitness for military service of every Italian male of conscription age. The main statistical issues in these data are variation in the conscription age and height-selective emigration and draft evasion. The first dataset, produced by the Italian National Institute of Statistics (Istat), provides mean height at the national level (1854-1980 cohorts) and by region (1927-1980 cohorts), normalized to age 20 (up to the 1953 cohort) to control for changes in the conscription age. The second dataset, assembled by Brian A'Hearn, Giovanni Vecchi, and myself (henceforth APV) from reports housed at the library of the Italian Parliament, consists of tabulated height frequencies at a fine geographical level for each cohort from 1846 to 1910. This dataset has been used by APV (2007) to estimate how the height distribution (not just its mean) changes with conscription age and emigration or draft evasion. Their method is semi-parametric in nature because it does not require height to be normally distributed-a problematic assumption when the nutritional and health environment is poor, or at ages before adult height is reached. I employ their method to construct "counterfactual" distributions of height (or summaries of these counterfactual distributions, such as the mean and the standard deviation) corresponding to different ages and a proportion of absentees ( 5 percent) equal to the long-run average.

For the cohorts born between 1940 and 1980, I also use the micro-data from the European Community Household Panel (ECHP), a multipurpose annual longitudinal survey carried out between 1994 and 2001 in 15 European countries and cross-sectionally representative of the noninstitutionalized population. The last four waves of the ECHP (1998-2001) contain information on self-reported height without shoes for ten countries (Austria, Belgium, Denmark, Finland, Greece, Ireland, Italy, Portugal, Spain and Sweden). The data contain no missing value on height, but are very noisy. The other statistical issues in these data are measurement error in reported height and height-selective migration and mortality.

\section{Mean Height and Real Incomes}

Figure 1 shows the time profiles of real incomes (right axis, on log scale) and mean height at age 20 (left axis), both measured in the year a cohort is born. Overall, the two profiles have a similar U-shape, with the trough in the mid-1800s.

For the 1730-1840 cohorts, I report estimated mean height at 5-year intervals for a 20 -year old soldier from Lombardy (always one of the richest regions of Italy), computed by taking a population-weighted average of the provincial means estimated by A'Hearn (2003). Over this period, both real incomes and mean height display a clear downward trend. The index of GDP per capita $(1911=100)$ falls from 71.7 in 1730 to 63.1 in 1840 , while mean height falls from $167.8 \mathrm{~cm}$ for the pre-1755 cohorts to 164.1 $\mathrm{cm}$ for the post-1830 cohorts, with much of the decline completed by the early 1800s. As argued by A'Hearn (2003), the negative trend of height "places northern Italy firmly within the broad European experience. A fall in heights of this magnitude over the second half of the eighteenth century was common across much of Europe, affecting countries as diverse as the Habsburg provinces in Eastern Europe, Bavaria, France, the British Isles, and Sweden. Only from the 1820s do developments in Northern Italy appear to diverge from those elsewhere. While heights in most countries increased slowly but steadily from turn-of-the-century troughs, average stature in Lombardy failed to consolidate an early 1820 s recovery and sank back to secular lows." Despite the negative trend, however, mean height in Lombardy falls in the middle of the range for several European countries in the 1830s, below England, France, the Netherlands, and Sweden, but above other provinces of the Habsburg Empire (A'Hearn 2003).

For the 1846-1910 cohorts, I report mean height at age 20 for Lombardy and Italy at the pre-1919 borders, estimated as in APV (2007). Though not shown here, the mean for Italy agrees closely with the series published by Istat. Height and real incomes grow together after the Italian unification. However, while the level of 


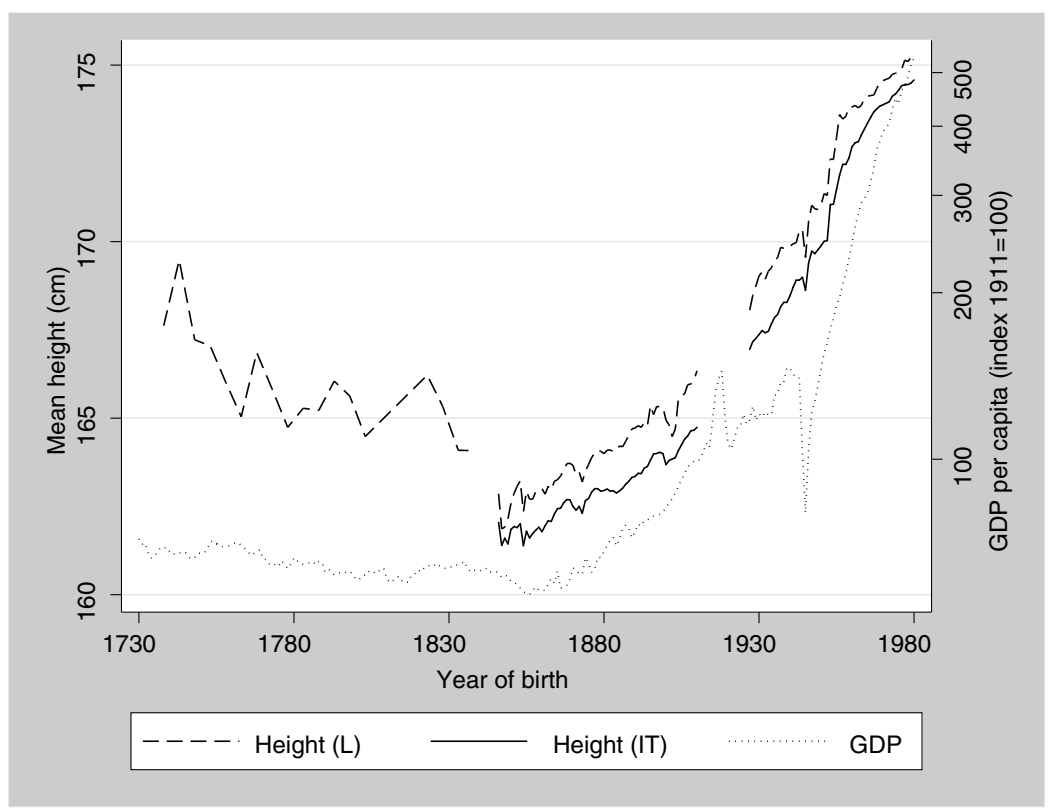

Figure 1. Italian Real GDP Per Capita and Mean Height at Age 20 IN LOMBARDY (L) AND ITALY (IT)

GDP per capita of 1730 is reached again in the 1880 s, mean height of the $1735-1740$ cohort in Lombardy is reached again only later, by those born in the 1920s. A strong and positive correlation can also be found between height and a host of other aggregate welfare indicators (food consumption, caloric intake, life expectancy at birth, gross enrollment rate in primary school, etc.).

For 1927-1980 cohorts, I report the Istat series of mean height for Lombardy and Italy at current borders. Height and real incomes continue to grow between the two World Wars. After falling during WWII, they resume growth at a very fast pace up to the early 1960s, when their growth loses steam. The slowdown of height growth is more pronounced, as one would expect if the height/income relation is increasing and concave, and is quite sudden in Lombardy, where immigration from the Southern regions characterized by shorter mean height may matter.

Figure 2 uses the same data as Figure 1, but looks at the height/income relation by plotting mean height against real incomes (on log scale). The solid lines are the predicted values from OLS regressions of mean height on a quadratic polynomial in log income, estimated separately for each of the three periods (with 1945 omitted). Ignoring the special pattern for the 1730-1840 cohorts, which may reflect problems with the available data, Figure 2 may be interpreted in two ways. One interpretation is that the height/ income relation is increasing and concave, but not stable over time. This lack of stability may reflect either data problems, especially with the measurement of GDP per capita, or shifts due to the omission of relevant variables, especially those summarizing the disease environment. No matter what its source is, it would give no solid base for inferring changes in real incomes from those in mean height. The other interpretation is that there exists a stable, increasing, but not concave height/income relation. This lack of concavity would destroy the negative relationship between mean height and income inequality stressed by Richard Steckel (1995).

The catch-up of Italian real incomes with respect to Europe, especially after WWII, is well documented (see for example Felice 2006). How about height? For the post-1950 cohorts, Carlos Bozzoli, Angus Deaton, and Climent Quintana-Domeque (2007) show strong convergence of Mediterranean countries (Greece, Italy, and Portugal) to the other country group in their study (Austria, Belgium, Denmark, Finland, Ireland, Sweden, the United Kingdom, and the United States). Table 1 provides more detail by 


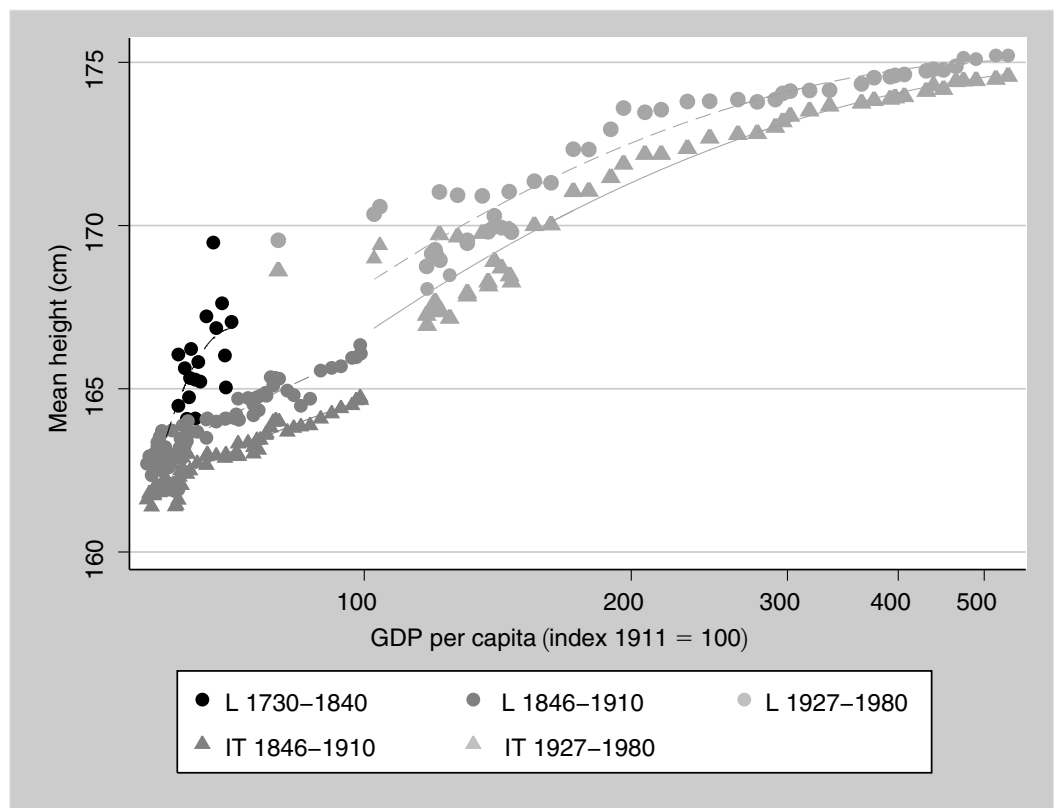

Figure 2. Mean height in Lombardy (L) ANd Italy (IT) against Italian Real GDP Per CAPIta

presenting the results of regressing individual height on a constant, a quadratic cohort trend, total (annual) household income, divided by an "equivalent scale" that takes into account the size and composition of the household, and indicators for secondary and tertiary education. I use the micro-data from the ECHP, keeping only people born between 1940 and 1980 who are not foreign-born. Estimates are presented separately for Italy, the other Mediterranean countries (Greece, Portugal, and Spain), and the Nordic countries (Denmark, Finland, and Sweden) in the ECHP. The intercept is an estimate of the mean height for the reference person - a male born in 1950, with the lowest educational attainment, and equivalized household income equal to 12,000 euros. The table shows a flattening of the trend toward increasing height in the Nordic countries, the catch-up of Italy, and its faster height growth relative to the other Mediterranean countries. Interestingly, both the "schooling gradient" and the "income gradient" are stronger in the Mediterranean countries than in the Nordic countries. However, while the "income gradient" is stronger in Italy than in the other Mediterranean countries, the opposite is true for the "schooling gradient."
Table 1-Height Regressions by Country, 1940-1980 COHORTS

\begin{tabular}{lccc}
\hline \hline & Italy & GPS & DFS \\
\hline Cohort & 0.192 & 0.125 & 0.156 \\
& $(0.017)$ & $(0.012)$ & $(0.014)$ \\
Cohort sq. & -0.001 & 0.000 & -0.003 \\
& $(0.001)$ & $(0.000)$ & $(0.001)$ \\
Secondary ed. & 1.760 & 3.676 & 0.792 \\
& $(0.188)$ & $(0.141)$ & $(0.205)$ \\
Tertiary ed. & 2.218 & 3.730 & 1.644 \\
& $(0.308)$ & $(0.166)$ & $(0.229)$ \\
Income & 0.121 & 0.080 & 0.055 \\
& $(0.011)$ & $(0.008)$ & $(0.010)$ \\
Constant & 170.906 & 169.959 & 177.472 \\
& $(0.147)$ & $(0.097)$ & $(0.190)$ \\
$N$ & 20,615 & 41,607 & 19,539 \\
$R^{2}$ & 0.118 & 0.137 & 0.0391 \\
RMSE & 6.76 & 7.07 & 6.66 \\
& & &
\end{tabular}

Notes: GPS: Greece, Portugal, and Spain; DFS: Denmark, Finland, and Sweden. OLS coefficients with estimated standard errors in parentheses. Standard errors are robust to heteroskedasticity and clustering by individuals.

\section{Height Dispersion}

Dispersion is another aspect of the height distribution that has recently received some attention. For example, Carles Boix and Frances 
Rosenbluth (2006) argue that height dispersion in an adult population sheds light on inequality within social groups in the access to net nutrition, while Alexander Moradi (2006) presents a simple model of how the height distribution responds to changes in income inequality.

The evidence on long-run trends is limited, and lack of data prevents me from analyzing empirically the relation between height dispersion and income dispersion. For Lombard soldiers born between 1730 and 1840, A'Hearn (2003) estimates a standard deviation (SD) of 6.1 $\mathrm{cm}$. This value is relatively low, but may depend on recruiting procedures, and is obtained after controlling for a rich set of covariates. For the 1846-1910 cohorts, the SD at age 20 has a very similar trend for Lombardy and Italy as whole, falling substantially between the 1846 and the 1890 cohorts (from about 7.5 to about $6.5 \mathrm{~cm}$ ), and then rising modestly in the next two decades. The average SD at age 20 over this period (6.8 $\mathrm{cm}$ for Lombardy and $6.9 \mathrm{~cm}$ for Italy) is in line with the range $(6.8-7.0 \mathrm{~cm})$ reported by Luciano Terrenato and Laura Ulizzi (1983) for selected cohorts born between 1874 and 1960. At the national level, the ECHP shows an increase of the SD from about $6.5 \mathrm{~cm}$ for those born in the 1930s to about $7 \mathrm{~cm}$ for those born after 1960, possibly because of height-selective mortality.

The national variance of height may be decomposed into the sum of between- and within-region variation. Regional differences in mean height are sizeable and persistent (Emilia Arcaleni 2006). With the important exception of the Northeast, they are also highly correlated with regional differences in real incomes. In particular, the North is always taller than the South (by 3 to $5 \mathrm{~cm}$ at age 20), while the difference between the tallest regions of the North (Venetia and Friuli) and the shortest of the South (Basilicata and Sardinia) ranges between 5 and $9 \mathrm{~cm}$. The variability between regions, however, is dwarfed by within-region variability, which represents 90 percent or more of total variance.

Decreasing variability within regions and a switch from regional convergence to divergence are prominent features of the 1846-1910 period. Up to 1880 , both the within- and the betweenregion components contribute to declining variance of height at age 20. Between 1850 and 1880, the within-region component falls from 52.5 to $40.1 \mathrm{~cm}^{2}$, while the between-region component falls from 4.1 to $3.0 \mathrm{~cm}^{2}$. During this period, mean height tends to increase more in the provinces where it was initially lower, mainly in the South. With the 1880s, the trends change. Within regions, average variability stops falling. Between regions, a process of outright divergence takes hold. Height growth accelerates in the North, especially in the provinces of early industrialization in the Northwest (an area that came to be known as the Industrial Triangle in this period), while slowing down in the South.

\section{Height and the Adolescent Growth Spurt}

For the cohort beyond 20 years of age, my data show no evidence of the striking decline of height dispersion observed at earlier ages for the 1846-1910 cohorts. This different pattern by age prevents interpretations that mechanically relate height dispersion to inequality in net nutrition, or its changes over time to equity aspects of economic development.

To interpret the observed pattern, I first look at the adolescent growth spurt (AGS) in the contemporary United States. Figure 3 shows the age-profile of median height, growth velocity (the annualized change in median height), and quantile-based measures of dispersion and skewness - the interdecile range (IDR) and the ratio between the deviation of the ninetieth percentile from the median and the deviation of the median from the tenth percentile. The data, for the year 2000 are taken from the Web site of the National Center for Health Statistics. For boys, velocity and dispersion peak at age 14 and left-skewness at 15 . For girls, velocity and left-skewness peak at age 12 and dispersion at 11.5 , as the onset of puberty is earlier. By age 19 , for both boys and girls, velocity has fallen to almost zero, dispersion has settled at a lower level, and the height distribution looks approximately normal.

The poor nutritional and health environment, typical of earlier periods, but also of many developing countries today (Phyllis Eveleth and James Tanner 1990; Deaton 2007), delayed and prolonged the AGS beyond the age of 20. This suggests that the different patterns of height variability by age observed for the 1846-1910 cohorts may be driven largely by an earlier onset of the AGS. Figure 4 shows that this is indeed the case. The figure is the analogue of Figure 3, but has a somewhat different age range and compares Italian males of different cohorts. It has 


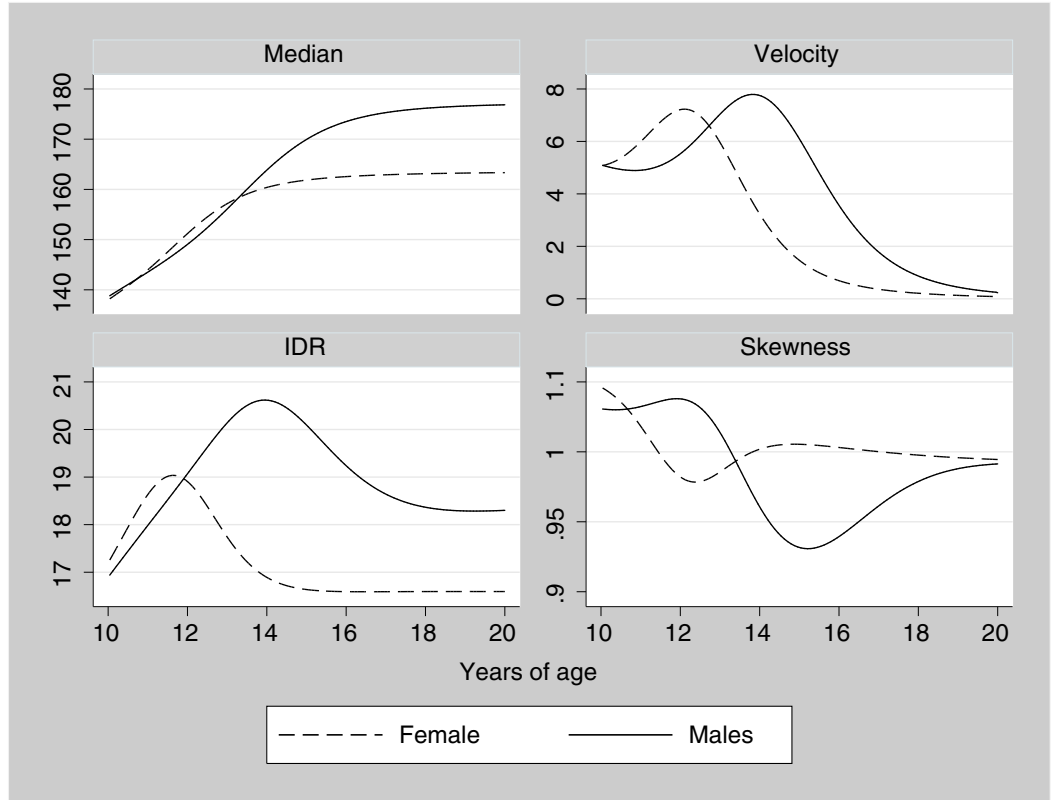

Figure 3. The AGS in Contemporary US, Year 2000

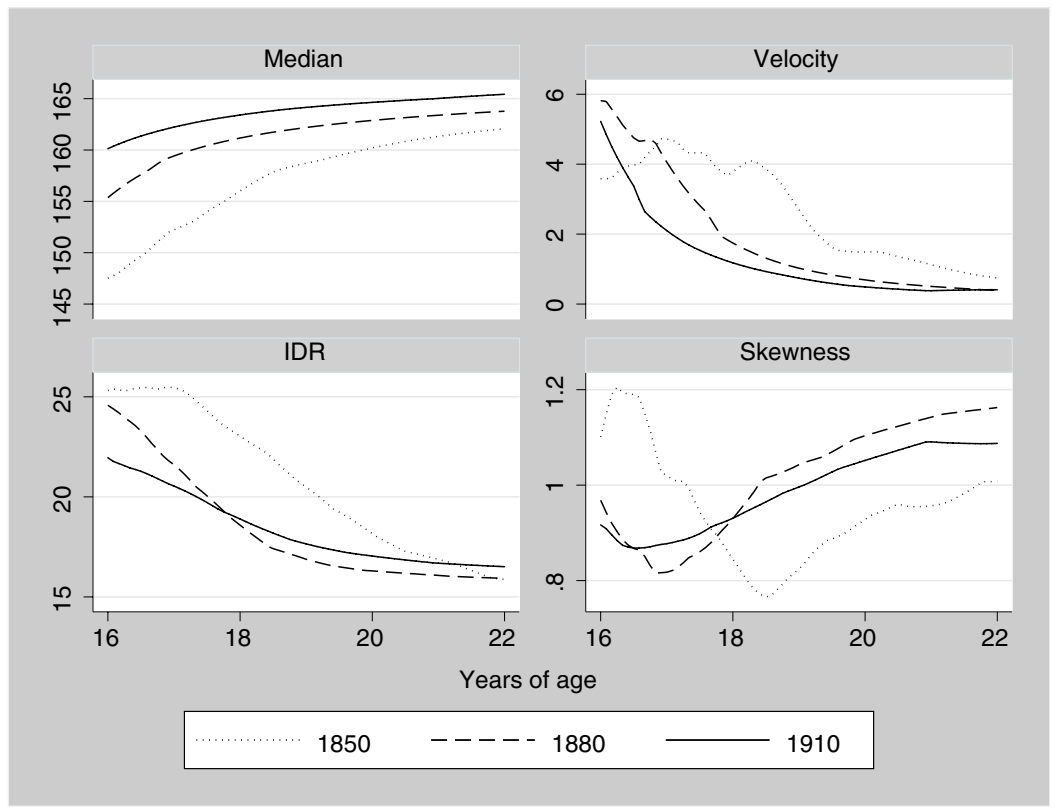

Figure 4. AGS among Italian Males Age 16-22 By Birth Cohort

been constructed first by evaluating the counterfactual height distributions obtained, using the method in APV (2007), for each month of age between 16 and 22 years for each cohort, and then inverting them to compute the various quantiles. Compared with contemporary US boys, median height and velocity are lower and peak-dispersion and left-skewness are higher 
but, qualitatively, these profiles match well those in Figure 3. The age profiles of velocity, dispersion, and skewness of the 1850 cohort resemble those of contemporary US boys, but are shifted to later ages. Moving to subsequent cohorts, the change in the location of the profiles reveals that the onset of the AGS occurs earlier and earlier, and that the age of peak-dispersion and asymmetry of the height distribution shifts to the left, from over 18 years for the 1850 cohort to about 16 for the 1910 cohort. The richness of the conscript data allows me to obtain similar graphs by geographical area. These graphs show an earlier onset of the AGS in the North and, over time, its more evident occurrence at earlier stages in the provinces of the Industrial Triangle.

This effect may be important, both historically and in poor countries today, for it implies an earlier ability to carry out tasks that are either physically demanding or require improved cognitive and relational skills. For women, because of the association between height and pelvic size, it may also imply a reduction of the risks associated with early childbearing. Both effects may feed into the pace of economic development.

\section{REFERENCES}

A'Hearn,Brian.2003. "Anthropometric Evidence on Living Standards in Northern Italy, 1730 1860." Journal of Economic History, 63(2): $351-81$.

A'Hearn, Brian, Franco Peracchi, and Giovanni Vecchi. 2007. "Living Standards and the Distribution of Heights: Italy, 1855-1910."

Princeton University Center for Health and Wellbeing Working Paper 229.

Arcaleni, Emilia. 2006. "Secular Trend and Regional Differences in the Stature of Italians, 1854-1980." Economics and Human Biology, 4(1): 24-38.

Boix, Carles, and Frances Rosenbluth. 2006. "Bones of Contention: Political Economy of Height." Unpublished.
Bozzoli, Carlos, Angus Deaton, and Climent Quintana-Domeque. 2007. "Child Mortality, Income and Adult Height." National Bureau of Economic Research Working Paper 12966.

Deaton, Angus. 2007. "Height, Health, and Development." Proceedings of the National Academies of Science, 104(33): 13232-37.

Eckaus, Richard. 1961. "The North-South Differential in Italian Economic Development." Journal of Economic History, 21(3): 285-317.

Eveleth, Phyllis, and James Tanner. 1990. Worldwide Variation in Human Growth. 2nd ed. Cambridge, UK: Cambridge University Press.

Felice, Emanuele. 2006. "Income and Human Development: Measuring Regional Disparities in Income." Unpublished.

Fogel, Robert. 1994. "Economic Growth, Population Theory, and Physiology: The Bearing of Long-Term Processes on the Making of Economic Policy." American Economic Review, 84(3): 369-95.

Lutz, Vera. 1962. Italy: A Study in Economic Development. Oxford: Oxford University Press.

Maddison, Angus. 1995. Monitoring the World Economy: 1820-1992. Paris: Development Centre of the Organisation for Economic Cooperation and Development.

Malanima, Paolo. 2007. “The Italian GDP, 13001913." Unpublished.

Moradi, Alexander. 2006. "On Inequality in Net Nutritional Status." http://www.economics. ox.ac.uk/Members/alexander.moradi/heightinequality.pdf

-Silventoinen, Karri. 2003. "Determinants of Variation in Adult Body Height." Journal of Biosocial Science, 35(2): 263-85.

Steckel, Richard. 1995. "Stature and the Standard of Living." Journal of Economic Literature, 33(4): 1903-40.

Terrenato, Luciano, and Laura Ulizzi. 1983. "Genotype-Environment Relationships: An Analysis of Stature Distribution Curves During the Last Century in Italy." Annals of Human Biology, 10(4): 335-46. 